\title{
From Literature to Alternate Reality Games: Prerequisites, Criteria, and Limitations of a Young Adult Novel's Transformational Design for Educational Purposes
}

\author{
Evangelia Moula1, Konstantinos Malafantis ${ }^{2}$ \\ ${ }^{1}$ Hellenic Open University, Patras, Greece \\ ${ }^{2}$ National and Kapodistrian University of Athens, Athens, Greece \\ Email: moulaevang@gmail.com,kmalafant@primedu.uoa.gr
}

How to cite this paper: Moula, E., \& Malafantis, K. (2019). From Literature to Alternate Reality Games: Prerequisites, Criteria, and Limitations of a Young Adult Novel's Transformational Design for Educational Purposes. Advances in Literary Study, 7, 224-241.

https://doi.org/10.4236/als.2019.74014

Received: September 23, 2019

Accepted: October 21, 2019

Published: October 24, 2019

Copyright $\odot 2019$ by author(s) and Scientific Research Publishing Inc. This work is licensed under the Creative Commons Attribution International License (CC BY 4.0).

http://creativecommons.org/licenses/by/4.0/

\begin{abstract}
This study presents the process of the transformational design of a young adult novel into an alternate reality game (ARG) for educational purposes, creating this way, an affinity space for students. Since one of the primary objectives of literature's curriculum is the cultivation of young people's reading for pleasure disposition-whose rate is declining - such a project could be a challenge and at the same time could open up a potential prospect of enhancing the positive response of young people towards literature. At the same time, the project supports a multidimensional approach to the literary phenomenon as a means of promoting a wide range of learning goals. The contribution of this venture is that although ARGs have been used in the educational field before, there is no evidence for such a transformational process in the corresponding literature. Design issues, the main characteristics of the ARGs, the criteria and the motivational factors of successful ARGs, as well as the inherent limitations of such a project. The project was applied to the Greek young adult novel: Leros' Code by Kostas Stoforos (Stoforos, 2016) and the derivative ARG was implemented during the 2018-19 school year in secondary education students in Rhodes, Greece as part of a postdoctoral research (ongoing). The whole project aimed to examine how an ARG could be compatible with the literary curriculum and the teaching mechanics and even more, how it could promote collaborative learning and literacy practices of the $21^{\text {st }}$ century. The data collection and processing will take place within the ensuing months, soon after which, we will be able to announce our final conclusions.
\end{abstract}

\section{Keywords}

Literary Education, ARG, Transformational Design, Affinity Spaces, 


\section{Introduction: ARG as a Narrative Means and Its Particularities}

In the last decades, research about the reading habits of young people and specifically about reading literature for pleasure has been multiplied, in which there seems to exist a negative correlation between literary reading and the emergence-not to say dominance-of the digital environments and the internet as socializing and entertaining landscapes (Twenge et al., 2018). New technologies, however, open up new perspectives on the creation, dissemination, and reception of literary narrative, as this is increasingly being transferred to digital environments. Multimodal and multimedia narrative entities supplant the monomodality of speech as the main expressive means of literary narrative, proposing new digital genres (Askehave \& Nielsen, 2005). By examining the four basic properties of the concept of the medium, we find that all, material, sensorial, spatiotemporal and semiotic features (Ellestrom, 2010: p. 15) of literature as a medium, are being revised. Equally, the so far mainly passive, lonely, sophisticated and reflective manner of reading is being undermined. From the classic works of literary art to the printed literary texts imbued with elements of Internet aesthetics (Yiannicopoulou, 2007), to the interactive hypertexts and finally to the transmedia narratives (Moula \& Malafantis, 2018) a subversive new philosophy of reading is being established, in which indispensable condition is the recipient's active engagement and participation in the shaping of the story and to regulate the rate of his/her engagement with the narrative. According to Ryan (2006: p. xvii) narrative, either in the old or in the new media, as an invariant core of meaning, has transcultural, transhistorical, and transmedial identity. The difference lies in the expressing modes the digital narrative is tied to, which are the simulative, the participatory and the emergent mode. Viewing user participation as the most important of the properties of digital media, representatives of this approach conceive interactivity as a compatible potential with narrative immersion, still to be explored. Jenkins (2004) contends that the discussion so far, from the ludologists' point of view:

"has operated with too narrow a model of narrative, one preoccupied with the rules and conventions of classical linear storytelling at the expense of consideration of other kinds of narratives, [....] which seek to balance between the competing demands of narrative and spectacle”.

ARG is a relatively new category of storytelling - transmedia, pervasive, interactive and playful-developed in online interactive environments but also utilizing real-world communication methods, whose popularity is steadily increasing. ARGs as immersive story-game hybrids favor participatory storytelling, 
problem-solving and agency by the reader-player.

Even more as a form of transmedia storytelling, they engage players in missions to collectively uncover, interpret, and reassemble the fragments of a story which is distributed across multiple media, platforms, and locations (Bonsignore et al., 2013). Being transmedia productions, one of their main advantages lies in their ability to "transport the players to a fictional world superimposed on the reality of everyday life" (Dena, 2008).

ARGs have nothing in common with most Internet or video games of the past. One of their main goals is to deny and disguise the fact that they are even games at all, making their main principle what has come to be called the TINAG philosophy, standing for This Is Not A Game (Szulborski, 2005: p. 7). To be more accurate, they deliberately blur the boundaries between in-game and out-of-game experiences and elements of the plotline may be provided to the players in almost any form (Gosney, 2005: p. 2).

Nevertheless, first and foremost, ARGs have primarily been designed as storytelling vehicles (Martin et al., 2006), combining interactivity with immersion. One way to capitalize on a narrative in an ARG is to reveal parts of it gradually as a reward for achieving specific goals from students (Bopp, 2008).

\subsection{ARGs in Education: A Literature Review}

ARGs occupy five distinct areas as following ${ }^{1}$ : Promotional games, grassroots games, productized or Commercial, singe-player games and training or educational games.

Their potential as educational strategy has only recently been discovered, still scarcely. In the early stages, ARGs' applications were mainly targeted at higher education, but from 2010 onwards they appear at the other educational levels too.

Initiatives such as "Blood on the Stacks" (2006), "World without oil" (2007), "The Great History Conundrum" (2008), ARGOSI (2008), Just Press Play "EVOKE" (2010) and "The Arcane Gallery of Gadgetry" (2011) are some of the ARGs that have been successfully implemented in the context of education.

In primary and secondary education there have been some early initiatives such as HARP (2006), Ecomuve (2009) and Mentira (2009). These ARGs were designed by experts from top universities, like Harvard University, The University of Wisconsin, MIT and The University of New Mexico. In Europe, the EMAPPS (2005), funded by the Sixth Framework Program, was designed to offer enriched learning opportunities to 9 - 12-year-olds in their curriculum and beyond (Davies et al., 2006).

A literature review article, which aimed to catalog applied ARGs in education during the 2009-2016 period, through the search for: "gamification", "Alternate Reality Game" and "ARG in Education" on the ProQuest platform (Xiao et al., 2016), came up with the following findings: three ARGs that aimed at freshmen's orientation and induction (Viola quest, Who's Herring Hale, C's Day and FYC's

${ }^{1} 2006$ Alternate Reality Games White Paper-IGDA ARG SIG. 
the Day), two that aimed to strengthen the players' motivation to learn foreign languages and foster intercultural awareness (Tower of Babel, Global village playground), two about emergency response training (AtomicOrchid, Disaster Experience Game), one about physical education (The Skeleton Chase), one about science education (STEM ARG), and one about sexual education (the Source). Among the nine ARGs that were located, only one was being addressed to secondary education students. This was the Tower of Babel, which focused on secondary school students so as to motivate them to learn a modern foreign language (Connolly et al., 2011).

Again, in other cases students are becoming co-designers of the games, exploiting and enriching their digital literacy (Colvert, 2009) or individual teacher take initiatives-which are rare exceptions-, such as the case of John Fallon who turned the Odyssey into an ARG called: Dolus: Finding the Journal of Odysseus (Darvasi, 2014).

\subsection{Setting the Theoretical Background of Our Project}

Our project examines how an ARG can be compatible with literary curricular design and the delivery mechanics of the literature lesson. Even more, how an ARG can enable and foster collaborative learning and $21^{\text {st }}$-century literacy practices.

Key theories, having been considered as the substructure of our project were: affinity spaces, transformational play, multiliteracies and transfictionality (Ryan, 2008).

Our overarching goal had been to create a learning environment for students, resembling an affinity space. Such environments according to the literature may be physical, virtual, or blended spaces, where people interact around a common interest or activity (Gee, 2017). They offer multiple interest-driven trajectories and opportunities to learn with others, becoming an authentic participant (Squire, 2011).

The venture could also be placed within the frame of transformational play, since we designed the ARG for educational purposes. To achieve transformational impact through play one has to weave together particular design threads to form what it is referred to as substantive, immersive, impactive, and reflexive participation (Barab et al., 2010).

The transformation of a literary text into an ARG is also justified by the theory of multiliteracies (Cope \& Kalantzis, 2010) and the concept of transfictionality (Ryan, 2008). According to multiliteracies, the available design of a literary text was appropriated and was given a new representational form, in order to examine if this act of designing would affect the persons involved (redesigned). Besides, transfictionality examines and legitimizes changes in an original narrative, as parts of it migrate to other texts of the same medium or of other mediums or even become part of new narratives. According to Ryan's (2008) categorization, who distinguishes four kinds of transficitional transformations (expansions, modifications, transpositions, and citations), ours has been a trans- 
medial modification.

Having taken into account that one of the most effective ways of transmitting information and learning is through narratives, which are valuable support for learning, providing a sense of experience, organizing knowledge, raising problem-solving skills and increasing motivation (Hodhod et al., 2011), we chose to use this kind of hybrid narrative to promote a wide range of learning goals. The ARGs' major advantage is that they combine narrative with interactivity. Narrative, on the one hand, frames the abstract knowledge and connects it with life (Kapp, 2012) and the interactivity, on the other, allows the player to actively participate in the construction of the story, stimulates curiosity and imagination, and leads to "stealth" learning (Hodhod et al., 2011). Interactive narratives indirectly and subtly channel cognitive content as students are absorbed in story and play (Padilla-Zea et al., 2014).

\section{A Concise Description of the Young Adult Novel: Leros' Code by K. Stoforos and the Reasons Why It was Chosen}

The young adult novel Leros code (Figure 1) is a mystery-solving, adventure story which takes place on the Greek island, Leros. A group of four kids between 4 and 13 years old travel by boat for summer holidays to Leros island in the Aegean sea. A couple, Odysseus and Marina, accompany their kids Katerina and Zoe and their friends, Antigoni and Dimitris. In Leros, they will meet their grandfather (Odysseus' father), Lefteris and the grandma Zoi, who are already hosting their other grandchildren Zenovia and Yiannis. On the same boat and with the same destination, two other boys, Jason and Savvas travel also, accompanied by their aunt Kaliope, who happens to be an old friend and ex-girlfriend of Odysseus. The kids will get to know each other and become one big company. A "suspicious" conversation on the boat which Jason happened to overhear, triggers the story. The kids are entangled in unexpected adventures during their holidays which culminate on the $15^{\text {th }}$ of August, the great Christian holiday of the Assumption.

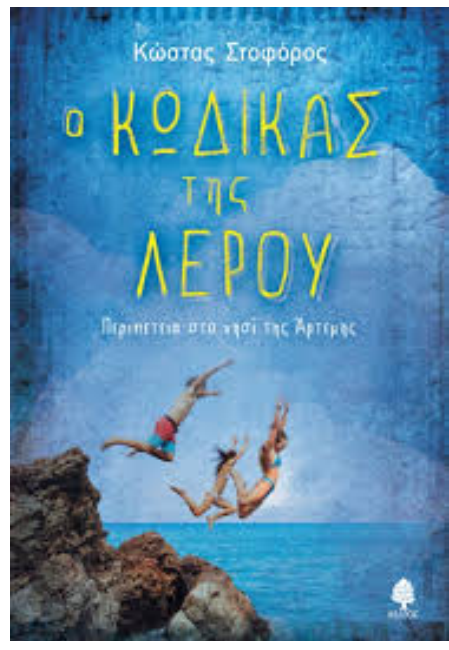

Figure 1. Leros' code. 
The "Leros' Code", which the kids try to locate and protect, is a manuscript describing the history and the customs of the island of Leros until the $19^{\text {th }}$ century, but they find out that part of it had been cut off by someone who knew the value of it long ago and had disappeared. At the same time the presence of the "Black Swan" in Leros the luxurious yacht of the powerful businessman Kurt Winder, complicates the situation.

As the thread of the story unfolds, significant elements from the geography and the history of the island and of Greece in general, with focus on the period of Italian occupation of the Dodecanese, are assimilated by the narrative. The encyclopedic elements are harmoniously integrated within the flow of the events, so that not only they are not being obtrusive, but they also contribute to the rising of the action.

Even more, through the adventure the readers are faced inadvertently with some key social or historical issues of major importance, which engage them emotionally and involve them mentally, such as the refugee issue, the distortion of truth by mass media, the way power controls and manipulates politicians, the methods used by the totalitarian regimes in modern Greek history in order to exterminate their political opponents, etc.

All the above characteristics of the specific narrative, the mystery-solving, the full of twists and subversions plot, the convincing characters, whom the students could identify with, the familiar settings (South Aegean Sea, Dodecanese) as well as the encyclopedic quality of the story combined with references to social issues that encourage reflection upon, contributed to the choice of the book to be used as the raw material of an ARG, which would be implemented in the context of a semi-formal educational process.

Thus the redesigned literary text into an ARG would at the same time be a source of reflection and a means of introducing students with key social and historical themes, not only at an informative but also at a critical-interpretive level. This would become feasible by intertwining missions and puzzles for students to perform or resolve, during the narrative process.

The implementation took place in the city of Rhodes, namely in two schools of Secondary Education ( $2^{\text {nd }}$ High School and $1^{\text {st }}$ Upper High School). The 68 students, who participated, were divided into two groups (one per school). It lasted 6.5 months from November to May, outside the school holiday season.

\subsection{Goals of the Project}

From the general aims of the literature curriculum ${ }^{2}$, the main ones, being served through the proposed approach are: cultural competence, communicative ability, emotional development, enrichment of the personal experience and sensitivity of students, cultivation of a critical position on basic issues of individual and social life, cultivation of responsible attitudes and beliefs, experiential participation, imagination development, language improvement, understanding of cer-

${ }^{2}$ http://www.pi-schools.gr/download/programs/depps/4deppsaps_Logotexnias_Gymnasiou.pdf. 
tain historical conditions and sensitization and development of a positive perception and attitude about modern multicultural and multiethnic society.

Moreover, since a major goal of literature curriculum and probably the greatest challenge of the teaching of literature is to foster a positive attitude towards literature, the transformation of a young adult novel into an ARG aspired to create favorable conditions for participation and involvement in the reading process for as many students as possible-and particularly for the reluctant ones-ultimately enhancing their reading for pleasure attitude. As it is pointed out in the curriculum: "The teacher's care is to avoid the monotony of the way of processing and to prefer a varied methodology through which to attract the student and engender the positive response of as many different readers as possible".

As the literary text is transformed into a radically different genre and transferred mostly to digital environments, an additional kind of goals, associated with these environments, was set. To be more specific, the project aimed at improving students' technological literacy (visual, informative, digital, web). This would be pursued through challenges and activities that foster the acquisition or the development of relevant skills in the above fields. e.g. students would be asked to observe images, edit and interpret them, search for information on the internet, compare sources and evaluate them, use applications to decipher messages, create digital artifacts in various web 02 environments or mobile apps, get accustomed to google maps, use Internet services to communicate and collaborate, etc.

In addition, the goals of the unified metaliteracies framework (Bonsignore et al., 2012) would be pursued too, according to which the participants should be able to: gather material and evaluate it, analyze, synthesize and reflect upon it, organize, solve problems and experiment, be creative, respect their partners, and collaborate with each other (according to the axes: gather, make sense, manage, solve, create, respect, collaborate). The UMF supports the notion that well-designed games engage students in "productive literacies" (Squire, 2011: p. 168).

\subsection{Resistances, Limitations and Difficulties}

One fundamental issue raised out of the particular circumstances of our ARG's creation. Since this ARG would not rely on an original concept but it would be the transformation of a pre-existing literary material-of the novel: Leros' Code-redesigning should take not violate the basic narrative principles of the original text, the characters, the space-time settings, and its value system. On the other hand, specific narrative components (extensive descriptions, retrospections, detailed historical data, and even the very exact sequence of events) should undergo modifications, or even be partly sacrificed to achieve a well-knit story to unfold within a reasonable time. However, the result should refer to the original text without any significant alterations or distortions.

Secondly, it is well-known that ARGs are based on the philosophy of This is not a game (TINAG) (McGonigal, 2003b). This means that they require the temporary suspense of disbelief of the players, or-better say-the players' per- 
form of belief (McGonigal, 2003a) in the events as real facts. It is vital that the boundaries between reality and fiction are blurred and that players are not certain if the narrative inhabits the real world or the world of the fictional story. One of the most problematic designing ideals is the desire to create a complete $360^{\circ}$ illusion of the game world (Koljonen, 2007; Waern et al., 2009), taken into account the Pinocchio effect (McGonigal, 2003b) which expresses the desire of the players to be absorbed by the game world as if it were real.

However, as this ARG was designed to take place in an educational contextan extracurricular activity program-the above fundamental requirement for its success was by definition abolished. The mere fact that it was addressed to students within a predetermined space and time frame, despite its playfulness and innovative character, undermined the desired illusion and belief performance and it was conceived as a supervised educational activity. This deprived the project of a significant part of the fascination about the unknown and the charm of the real mystery.

ARGs usually start with an element that appears supposedly random in some media and acts as a lure. In the most successful games, the participants had for a long time the impression that they were after a real mystery. In our case, students' participation necessarily required their recruiting, through a top-down process, (from the teacher to the students) which made the educational dimension of the project even more transparent.

Hence, another fundamental requirement of the ARGs could not be fulfilled, which was the creation of a "rabbit hole". This terminology refers to the first website, the original way of communication, or the puzzle from which an ARGs originates, and emanates from Louis Carroll's famous "Alice in Wonderland," where Alice's entry from the rabbit hole marks the beginning of the adventure (Tuten, 2008).

Moreover, as students' recruitment took place in the school environment, a major problem related to the interpretative frame of the educational environment arose. The frames are mental patterns through which the individual approaches social situations (Goffman, 1974). These are commonly accepted, they constitute social constructions and control one's expectations in specific circumstances.

Framework analysis has been applied to the game research field and it has been shown that established perceptions of games collide along the way with other emerging individual notions (Consalvo, 2009; Glas et al., 2011), but in the case under discussion, we had to face the existing notions of the students concerning a number of things involved.

The format of an ARG is difficult to comprehend by players entering the process with a previous gaming experience in other gaming forms and, concrete perceptions about what a game means and about what a narrative consists of (Kim et al., 2009). Even more strongly biased is the concept of learning itself and its appropriate processes. The previous familiarization of the players with self-contained 
experiences within a single medium, like electronic games or conventional narratives through a book or a movie, where information is transmitted top-down is an obstacle to understanding this new form that combines both of the above ingredients and forces them to contradict with their pre-existing views.

Besides, players come to play with different levels of interest (Azevedo, 2013) different skills (Jenkins et al., 2009) and different relationships with the field of games (Calabrese et al., 2013). This becomes tangible in students' suspicion or even their refusal to participate since the lack of familiarity or their total lack of information about this type of games strengthens their reticence against the unknown. Consequently, they express reluctance to try new things that could prove themselves a slippery ground for their prestige among the school community. The young adults are not comfortable with the "trial and error" principle of the ambiguous play. Fear of failure, lack of confidence in their skills and ignorance are the most serious obstacles to securing participation.

Even more, the given interpretive frame that implies educational activities as boring, games as non-reliable or approved educational activities, and literature as a teaching subject served better by the close reading approach, constitute an almost impermeable wall of denial and distancing, which was the major problem. This proves that literacy practices are patterned by social institutions and power relationships, and some literacies become more dominant, visible and influential than others (Barton \& Hamilton, 1998: p. 7).

So, not only the community had been shaped under the supervision and guidance of the designer and it was not self-regulated, but also the size of the community could not change decisively during the implementation, meaning that not many new players were attracted into the game, since it was considered as an entrenched members-only activity, although we did our best to establish a strong community (McGonigal, 2007).

Setting the rules of the game and the time limits of submitting the answers to a riddle or the responses to a mission, was an additive crux of the project. Although we defined the rules of the individual and group participation from the beginning, we were obliged to modify them from time to time, according to the difficulty of the mission and the players' readiness to respond, applying more flexible regulations.

Secondary issues were the monitoring and recording of the players' progress, as well as observing the time limits of each puzzle.

An additional point was the friction between group collectivity and individual distinction. Since it is expressly mentioned in the relative literature that individual recognition constitutes a strong motivation for participation, we added a competitive dimension in the game, trying not to undermine the collaborative side of it. So, we set badges for both individual and collective successful contributions to the game.

A last but not least issue was the low-level technological literacy of the students, which made it necessary to organize some preliminary meetings to fami- 
liarize the players with specific tools and digital environments, a fact that diminished players' anticipation.

\subsection{Our Response to the Transformational Design Prerequisites}

To design our ARG we took into account the findings of relative researches and tried to respond to different kinds of prerequisites.

To the key-design questions, regarding narrative, gameplay, learning and assessment, as set by Pellicone et al. (2017), we did not manage to deal with the first, which demands to engender the TINAG attitude, as already said.

- To the question: "How do we help novice ARG players envision gameplay across multiple platforms and modalities", we tried to answer by organizing preliminary meetings for the students to practice and familiarize with various platforms and tools.

- To the question: "How do we encourage co-creation of narrative, in order to deal with students' reservedness", we created various channels of in-play communication and aimed at the gradual deepening of students' confidence and the strengthening of their relations, which was the decisive factor to release their creativity and become active agents of the storyworld.

- To the question: "How do we sign-post in-game and out-of-game content", we chose a central person from the story to act as the communication channel, from whose website the orchestration of the story was taking place. $\mathrm{He}$ was also given the role of the players' companion and assistant and provided them with all the necessary help.

- To the question: "How can our narrative invite inquiry and play", we used the puzzles and the riddles as integrative parts of the narrative, which when solved revealed hidden clues of the story.

- To the question: "How do we design game mechanics in ARGs to provide guidance to a wide variety of learners" as well as to the question: "Where do the sources of direct instruction come from to effectively guide novice players", we activated a $24 / 7$ open communication with the puppetmaster, in order for the difficulties to be overcome discreetly and personalized.

- To the question: "What other game experiences activate learners' underlying interest, skill development and sense of identity", we created narrative cores with a variety of activities so as to be able to address a wide range of interests.

- To the last question: "How can we embed assessment more authentically into the interactive storyline or as an integral part of gameplay", we embedded as an inherent part of the narrative game-like activities, a scavenger hunt, a google form, a purpose game, a playposit edited video, two polls, a flipgrid and a paddlet.

Even more, having taken into account the 5 key principles which contribute to an enjoyable ARG experience (Macvean \& Riedl, 2011), and the motivational elements as mentioned by Whitton (2009) (Completion, Competition, Narrative, Puzzle-solving, Community, Creativity), we did the following: 
- we kept the strong narrative structure of the book, with slight modifications,

- we gave the story a modular structure which was spread throughout the world (digital and physical),

- we took good care of creating meaningful story pieces that all played a role in the formation of the game,

- we afforded the players the opportunity to interact with the system, by emphasizing on interactivity and we composed puzzles, riddles and missions so that they could be achievable by the skill level of the participants, providing them a sense of satisfaction and self-fulfillment.

- we tried to shape an effective, collaborative community and

- we gave the players the possibility not only to collaborate but also to compete, by setting an individual as well as a collective award and by keeping a regular shared board with the results and the won badges.

Another theoretical frame we took into account was the prerequisites of the transformational play, since we designed the ARG for educational purposes. So, we had to weave together particular design threads to form what it is referred to as substantive, immersive, impactive, and reflexive participation (Barab et al., 2010).

As far as the cognitive-substantive demand was concerned, given that the learning outcomes are not limited to knowledge of content but are observed in the development of skills, literacy, interest and empowerment, we defined the contents to be assimilated by the students, concerning historical and geographical facts and we incorporated them into missions to be accomplished for the narrative to unfold. Missions were sought to include challenges that exploited a representative range of digital environments and applications with an increasing degree of difficulty to create skill scaffolding.

Concerning the goal of immersive communication, which depends heavily on the persuasiveness of characters and the fictional world, certain data were created and disseminated on the Internet in order to animate the characters and provide them true-to-life identity. Thus, profiles were created on facebook and twitter, personal blogs, or websites which formed the communication channels with the players.

Missions to the real world of the immediate surroundings of the players were also planned and tried to also be realistically feasible. Equally challenging was the activation of members of the local community to participate in the game and enliven it.

At the level of the interaction (impactive communication) of the players with the game, there were created various digital challenges, online quizzes, fill-in or crossword puzzles, multiple-choice tests, encrypted messages in a variety of codes, augmented reality missions, google maps with embedded data, encrypted messages in a variety of codes, video chat threads and polls.

At specific key points, players were allowed the opportunity to influence the flow of the story by choosing between forking paths, in a way that the result 
could not overturn the original design, giving the players the illusion of power over the story, while the possibility to maneuver back to the main narrative was predicted.

Regarding the goal of reflective participation, there were opportunities for self-expression, points that allowed and supported the submission of personal views and the development of dialogue through which the possibility of negotiating assumptions and exchange arguments was provided. The players had the chance to discuss and reflect on their decisions and the effects of them in the game and in real life.

To be more specific, the narrative items were delivered in a variety of ways.

In particular, one profile was created on facebook (iasonas daimonios) (Figure 2), two on twitter (Savvas Kortesis, @KortesisSavvas and Antonis Limenikos, @limenkos), (Figure 3), four blogs: https://blogs.sch.gr/moula/ (for Antigone), https://iasonasdaimonios.wixsite.com/dimitris (for Dimitris),

http://odysseuscorner.simplesite.com (for Ulysses) and https://egeomarenostrum.wordpress.com (for Ameglio) (Figure 4), as well as a slidewiki https://slidewiki.org/user/katerina (for Katerina).

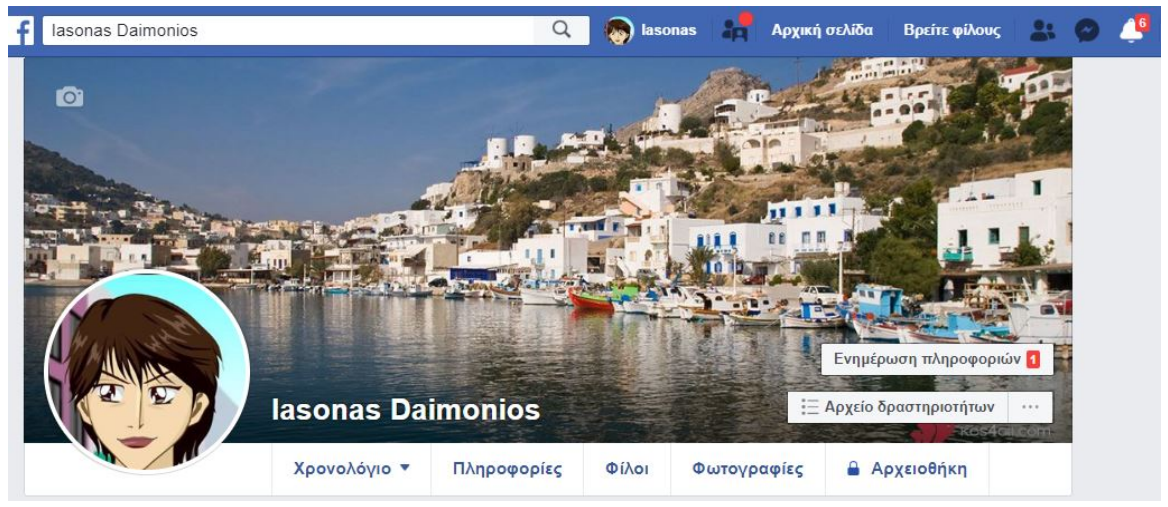

Figure 2. The protagonist's facebook page.

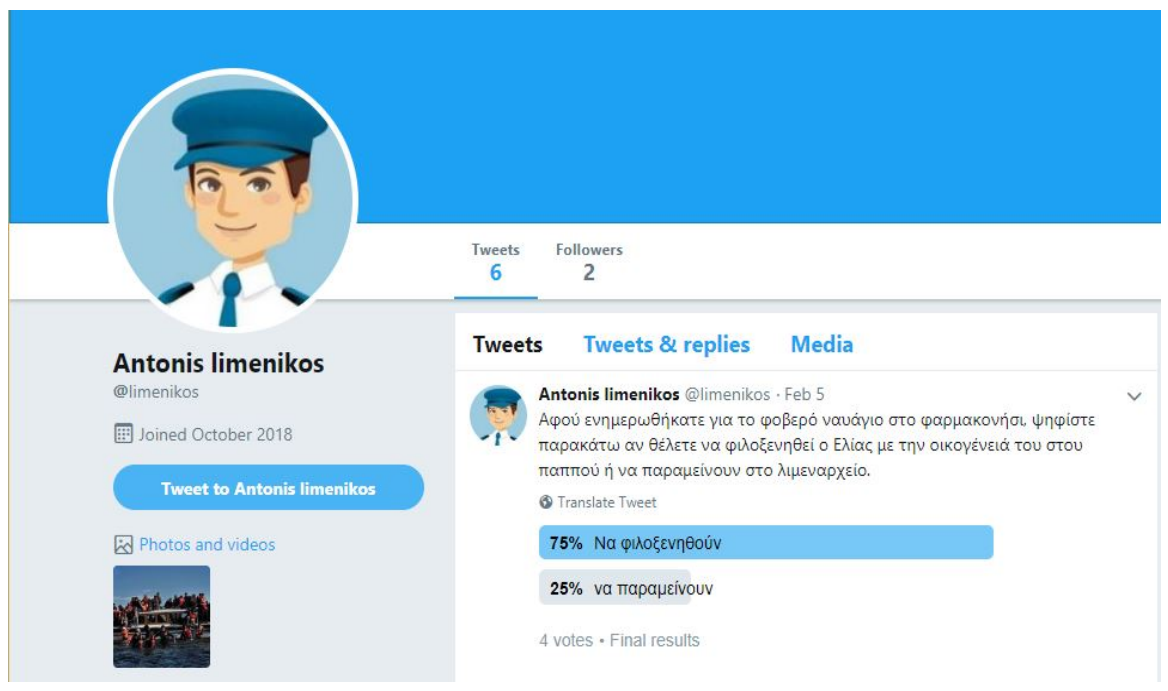

Figure 3. A character's twitter. 
We also created 2 voki (with spoken avatars), assumed conversation recordings in podcasts, 3 google maps with case-related data, 3 fake newsletters (Figure 5), 2 official documents, 5 qr codes, 2 blippar applications, 1 google form, 1 scavenger hunt, 2 interactive playposit videos, 1 content video, 1 purpose game (Figure 6), 5 encrypted messages with different codes (Mors, binary, Caesar's and Polybius's squares, number-letter matching), a mathematical problem, a cooperative wall. For the exchange of views, we created a chat thread on flipgrid and an online poll. We also used a temporary email service (getnada) and realworld communication methods, such as emails from heroes to participants, treasure hunting in the Old Town of Rhodes (Figure 7, Figure 8), internet search to cross-check information contained in storytelling, photo search on the images menu, online automatic translation, etc.

\section{Conclusion}

ARGs, no matter how complicated they may be on designing level, seem to

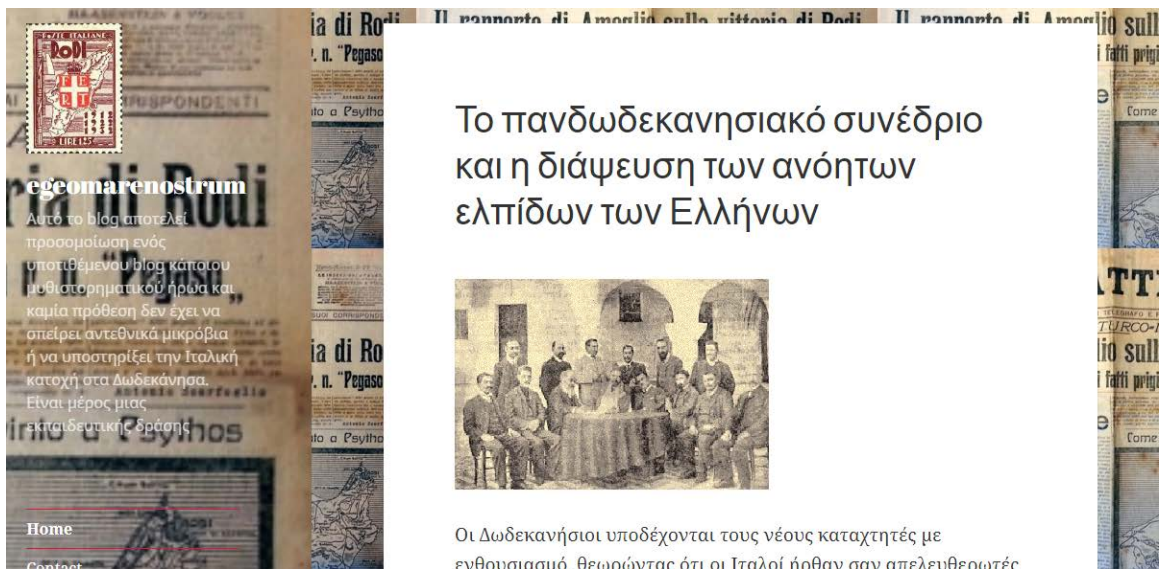

Figure 4. A character's blog with encrypted messages.

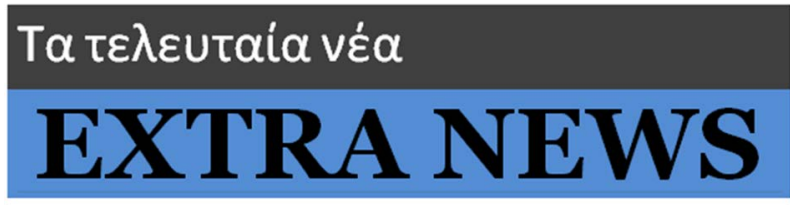

TODAY 17/08/17

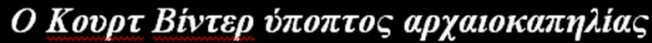
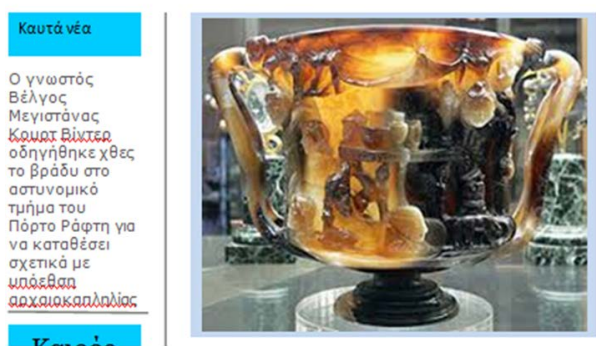

Като̇пIV катауүеגiac

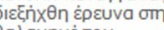

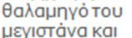

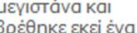

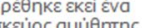

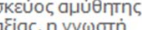
Koúna Tou Птол⿻上丨aiou. нદүıта́)

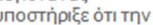

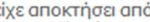
pxaıokánn $\lambda$ ouc $\mu$ бкопо va TnV

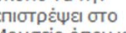
Mouбrio ónou kal

Figure 5. A fake cover-page of a newspaper. 


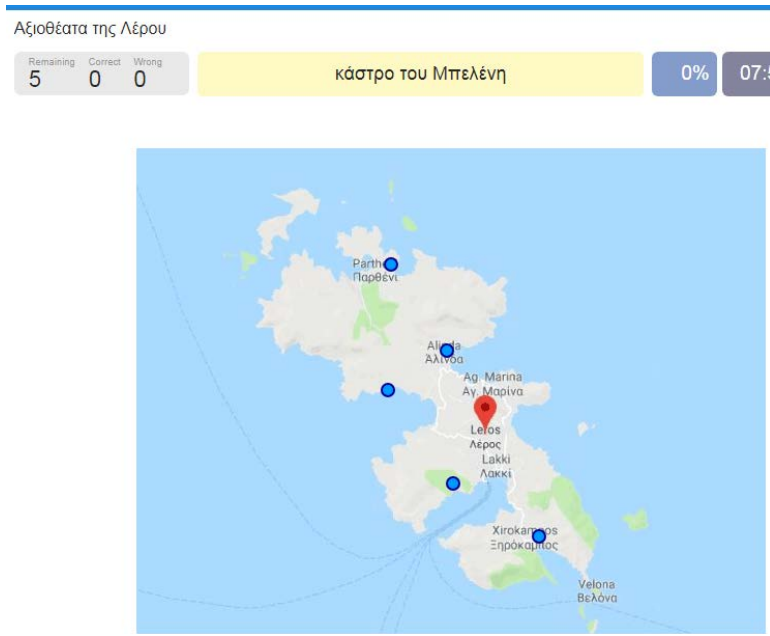

Figure 6. A purpose game about Leros island.

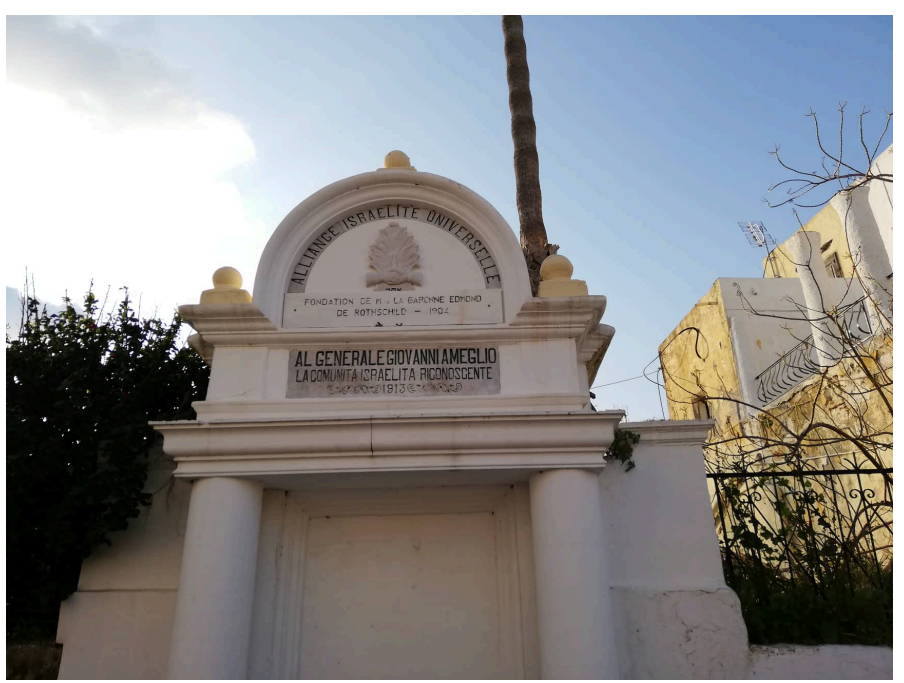

Figure 7. Giovanni Ameglio's monument-Old Town.

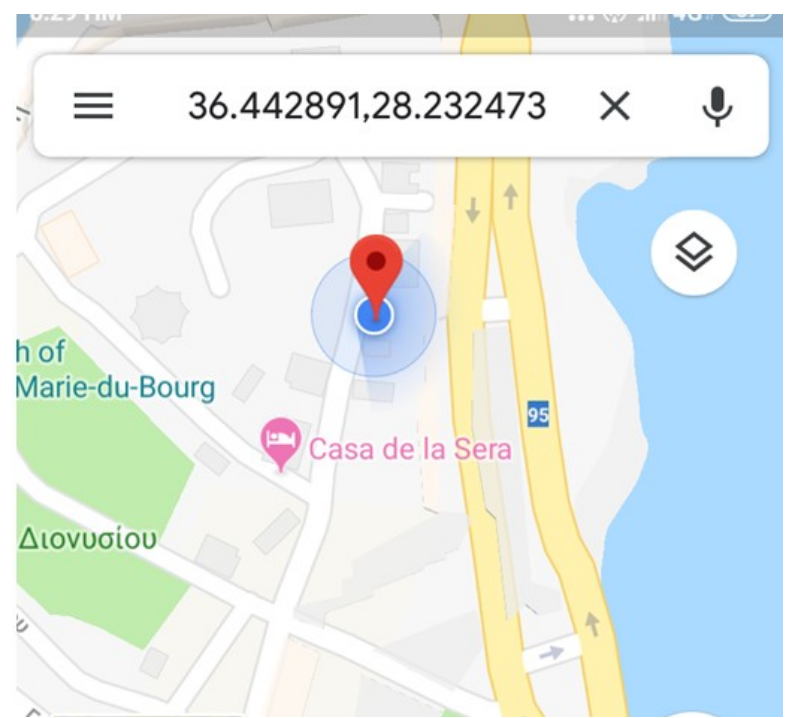

Figure 8. Its coordinates (treasure hunt). 
constitute a promising perspective in the field of education, concerning a wide range of $21^{\text {st }}$-century skills, of metaliteracies and even enhancing and improving young people's relation to literature.

Our venture set a multilevel goal frame and was it was implemented on secondary school students in Rhodes, Greece. Key theories, having been considered as the substructure of the project were: affinity spaces, transformational play, multiliteracies and transfictionality. Having followed the relative literature's findings, we tried to create an ARG for educational purposes, balancing between learning and fun.

Its implementation in an extra-curricular time-zone, as a supervised and coordinated by a teacher activity, deprived it at the beginning of a significant, potential part of the fascination about the unknown and the charm of participating in a real mystery. The main resistances came out of the educational frame, but soon the principal embarrassment and objections were suspended.

As the implementation of the ARG is in progress and we have not reached the point of the evaluation of the activity, through questionnaires, evidence (statistically active participation, community activation, sites' traffic, online quizzes) and interviews, it still remains to be examined whether the venture has achieved its goals in order to reflect upon the possibilities of further exploiting the concept of transforming literary texts to ARGs and suggesting possible improvements.

\section{Conflicts of Interest}

The authors declare no conflicts of interest regarding the publication of this paper.

\section{References}

Azevedo, F. S. (2013). The Tailored Practice of Hobbies and Its Implication for the Design of Interest-Driven Learning Environments. Journal of the Learning Sciences, 22, 462-510. https://doi.org/10.1080/10508406.2012.730082

Barab, S. A., Gresalfi, M., Dodge, T., \& Ingram-Goble, A. (2010). Narratizing Disciplines and Disciplinizing Narratives: Games as 21st Century Curriculum. International Journal of Gaming and Computer-Mediated Simulations, 2, 17-30.

https://doi.org/10.4018/jgcms.2010010102

Barton, D., \& Hamilton, M. (1998). Local Literacies: Reading and Writing in One Community. London: Routledge.

Bonsignore, E., Hansen, D., Kraus, K., \& Ruppel, M. (2012). Alternate Reality Games as Platforms for Practicing 21st-Century Literacies. International Journal of Learning and Media, 4, 25-54. https://doi.org/10.1162/IJLM_a_00086

Bonsignore, E., Hansen, D., Kraus, K., Visconti, A., Ahn, J., \& Druin, A. (2013). Playing for Real: Designing Alternate Reality Games for Teenagers in Learning Contexts. In Proceedings of the 12th International Conference on Interaction Design and Children (pp. 237-246). New York: ACM. https://doi.org/10.1145/2485760.2485788

Bopp, M. M. (2008). Storytelling and Motivation in Serious Games. Part of the Final Consolidated Research Report of the Enhanced Learning Experience and Knowledge Transfer-Project ELEKTRA. Nr. 027986. 
Calabrese, B., Hosun Kang, A., Tan, E., O’Neill, T. B., Bautista-Guerra, J., \& Brecklin, C. (2013). Crafting a Future in Science: Tracing Middle School Girls' Identity Work over Time and Space. American Educational Research Journal, 50, 37-75. https://doi.org/10.3102/0002831212458142

Colvert, A. (2009). Peer Puppeteers: Alternate Reality Gaming in Primary School Settings. In DiGRA Conference.

http://www.digra.org/digital-library/publications/peer-puppeteers-alternate-reality-ga ming-in-primary-school-settings/

Connolly, T. M., Stansfield, M., \& Hainey, T. (2011). An Alternate Reality Game for Language Learning: ARGuing for Multilingual Motivation. Computers \& Education, 57, 1389-1415. https://doi.org/10.1016/j.compedu.2011.01.009

Consalvo, M. (2009). There Is No Magic Circle. Games and Culture, 4, 408-417. https://doi.org/10.1177/1555412009343575

Darvasi, P. (2014). How to Transform Odyssey into an Epic Game in Alternate Reality. Mind Shift, KQED News.

https://www.kqed.org/mindshift/37884/how-students-can-channel-the-odyssey-into-a n-alternate-reality-epic

Davies, R., Krizova, R., \& Weiss, D. (2006). eMapps.com: Games and Mobile Technology in Learning. In European Conference on Technology Enhanced Learning (pp. 103-110). EC-TEL 2006 Crete, Greece. Berlin, Heidelberg: Springer. https://doi.org/10.1007/11876663_10

Dena, C. (2008). Emerging Participatory Culture Practices: Player-Created Tiers in Alternate Reality Games. Convergence, 14, 41-57.

https://doi.org/10.1177/1354856507084418

Ellestrom, L. (2010). Media, Modalities and Modes. In E. Lars (Ed.), Media Borders, Multimodality and Intermediality (pp. 11-48). Basingstoke: Palgrave-Macmillan. https://doi.org/10.1057/9780230275201_2

Gee, J. P. (2017). Affinity Spaces and 21st Century Learning. Educational Technology, 57, 27-31.

Glas, R., Jorgensen, K., Mortensen, T., \& Rossi, L. (2011). Framing the Game: Four Game-Related Approaches to Goffman's Frames. In C. Garry, V. K. Gosling, \& B. Light (Eds.), Online Gaming in Context: The Social and Cultural Significance of Online Games (pp. 141-158). London: Routledge.

Goffman, E. (1974). Frame Analysis: An Essay on the Organization of Experience. Cambridge, MA: Harvard University Press.

Gosney, J. (2005). Beyond Reality: A Guide to Alternate Reality Gaming. Boston, MA: Course Technology Press.

Hodhod, R., Cairns, P., \& Kudenko, D. (2011). Innovative Integrated Architecture for Educational Games: Challenges and Merits. In Transactions on Edutainment $V$ (pp. 1-34). Berlin, Heidelberg: Springer. https://doi.org/10.1007/978-3-642-18452-9_1

Jenkins, H. (2004). Game Design as Narrative. Computer, 44, 118-130.

Jenkins, H., Purushotma, R., Weigel, M., Clinton, K., \& Robison, Al. J. (2009). Confronting the Challenges of Participatory Culture: Media Education for the 21st Century. Cambridge, MA: MIT Press. https://doi.org/10.7551/mitpress/8435.001.0001

Kapp, K. M. (2012). The Gamification of Learning and Instruction: Game-Based Methods and Strategies for Training and Education. Hoboken, NJ: Wiley. https://doi.org/10.1145/2207270.2211316

Koljonen, J. (2007). Eye-Witness to the Illusion. An Essay on the Impossibility of $360^{\circ}$ 
Role-Playing. In J. Donnis, L. Thorup, \& M. Gade (Eds.), Lifelike (pp. 175-187). Copenhagen: Projektgruppen KP07.

Macvean, A. P., \& Riedl, M. O. (2011). Evaluating Enjoyment within Alternate Reality Games. In Proceedings of the 2011 ACM SIGGRAPH Symposium on Video Games (pp. 5-10). New York: ACM. https://doi.org/10.1145/2018556.2018558

Martin, A., Thompson, B., \& Chatfield, T. (2006). Alternate Reality Games White Paper. International Game Developers Association (IGDA).

http://org/arg/resources/IGDA-AlternateRealityGames-Whitepaper-2006.Pdf

McGonigal, J. (2003a). A Real Little Game: The Performance of Belief in Pervasive Play. In Proceedings of Digital Games Research Association. http://www.digra.org/digital-library/publications/a-real-little-game-the-pinocchio-effe ct-in-pervasive-play/

McGonigal, J. (2003b). This Is Not a Game: Immersive Aesthetics and Collective Play. In Melbourne DAC 2003 Streamingworlds Conference Proceedings.

McGonigal, J. (2007). The Puppet Master Problem: Design for Real-World, MissionBased Gaming. In P. Harrigan, \& N. Wardrip-Fruin (Eds.), Second Person. Cambridge, MA: MIT Press.

Moula, E., \& Malafantis, K. (2018). Children's and Young Adult Literature: From Isolation to Networking: The Internet as a Theme and as a Dynamic in the Young Adult Novel in Greece. Pedagogiki Epitheorisi, 35, 92-107. (In Greek)

Padilla-Zea, N., Gutiérrez, F. L., López-Arcos, J. R., Abad-Arranz, A., \& Paderewski, P. (2014). Modeling Storytelling to Be Used in Educational Video Games. Computers in Human Behavior, 31, 461-474. https://doi.org/10.1016/j.chb.2013.04.020

Pellicone, A., Bonsignore, E., Kaczmarek, K., Kraus, K., Ahn, J., \& Hansen, D. (2017). Alternate Reality Games for Learning: A Frame by Frame Analysis. In A. Garcia, \& G. Niemeyer (Eds.), Alternate Reality Games and the Cusp of Digital Gameplay (pp. 78-105). New York and London: Bloomsbury Academic.

Ryan, M.-L. (2006). Avatars of Story. Minneapolis/London: U of Minnesota Press.

Ryan, M.-L. (2008). Transfictionality across Media. In J. Pier, \& J. A. G. Landa (Eds.), Theorizing Narrativity (Narratologia 12, pp. 385-417). Berlin: De Gruyter.

Squire, K. (2011). Video Games and Learning: Teaching and Participatory Culture in the Digital Age. New York: Teachers College Press.

Stoforos, K. (2016). Leros Code. Athens: Kedros.

Szulborski, D. (2005). This Is Not a Game: A Guide to Alternate Reality Gaming. Incunabula.

Tuten, T. L. (2008). Advertising 2.0: Social Media Marketing in a Web 2.0 World: Social Media Marketing in a Web 2.0 World. ABC-CLIO. Westport, CT: Greenwood Publishing Group.

Twenge, J. M., Martin, G. N., \& Spitzberg, B. H. (2018). Trends in U.S. Adolescents' Media Use, 1976-2016: The Rise of Digital Media, the Decline of TV, and the (Near) Demise of Print. Psychology of Popular Media Culture, 8, 329-345. https://doi.org/10.1037/ppm0000203

Waern, A., Montola, M., \& Stenros, J. (2009). The Three-Sixty Illusion: Designing for Immersion in Pervasive Games. In Proceedings of the SIGCHI Conference on Human Factors in Computing Systems (pp. 1549-1558). Boston, MA: ACM. https://doi.org/10.1145/1518701.1518939

Whitton, N. (2009). Learning with Digital Games: A Practical Guide to Engaging Students in Higher Education. Abingdon-on-Thames: Routledge. 
https://doi.org/10.4324/9780203872987

Xiao, H., Zhang, H., \& Zane, M. R. (2016). Alternate Reality Game in Education: A Literature Review. In Proceedings of the International Conference of the Australian Association for Research in Education 2016: Transforming Educational Research. https://www.researchgate.net/publication/320395673

Yannicopoulou, A. (2007). Hypertextual Elements in the Interactive Fiction of Trivizas. Bookbird, 45, 15-22. 